\title{
MODERN METHODS OF PREVENTION AND TREATMENT OF COMPLICATIONS OF CERVICAL ESOPHAGO-ORGAN ANASTOMOSIS AT ESOPHAGOPLASTY
}

DOI: $10.36740 /$ WLek202008120

\author{
Volodymyr 0. Shaprynskyi, Yevhen V. Shaprynskyi, Mustafa Bassam Hussein, Oleg 0. Vorovskyi, Yaroslav V. Karyi, \\ Liudmyla A. Shaprynska, Serhii P. Dmytryshyn \\ NATIONAL PIROGOV MEMORIAL MEDICAL UNIVERSITY, VINNYTSIA, UKRAINE
}

\begin{abstract}
The aim: To improve the results of operative treatment of esophageal strictures by decreasing the rate of failure and stricture of cervical esophago-organ anastomoses. Materials and methods: There were 45 patients with post-burn corrosive gullet strictures, 17 patients with postoperative corrosive strictures, 10 patients with peptic strictures secondary to reflux-esophagitis, 42 patients with esophageal cancer strictures. The patients were divided into two groups: the comparison group - 55 persons and the main group - 59 persons. Patients of comparison group underwent surgical treatment of esophageal strictures according to classic protocols and standards. In the main group of patients we applied proposed diagnostic algorithm with prediction of complication risk and the designed method of esophago-organ anastomosis formation.

Results: The results of operative treatment in patients with esophageal strictures showed the development of early postoperative complications in 59 individuals (51.75\%). In the postoperative period six patients died: four - in the comparison group and two - in the main group. Failure of cervical esophago-organ anastomosis and esophageal strictures occurred in 7 patients $(11.86 \%)$ of main group and 20 patients $(36.36 \%)$ of the comparison group $(p<0.05)$.

Conclusions: Application of method predicting the risk of complications of cervical anastomosis, treatment program and instrumental method of formation anastomosis resulted in reduced incidence of failure and strictures of esophago-organ anastomosis from $36.36 \%$ to $11.86 \%(p<0.05)$; decreased time of hospitalization - from $28.2 \pm 1.1$ to $21.5 \pm$ 0.5 bed-days $(p<0.001)$, postoperative period - from $20.5 \pm 1.1$ to $16.1 \pm 0.7$ bed-days $(p<0.01)$; decreased postoperative mortality - from $7.27 \%$ to $3.39 \%$.
\end{abstract}

KEY WORDS: anastomosis failure, stricture, treatment program

Wiad Lek. 2020;73(8):1696-1699

\section{INTRODUCTION}

In the course of modern history of esophageal surgery development, it appeared to be one of the most difficult areas of thoracoabdominal surgery. The use of modern technologies of the XXI century, including diagnostic methods, particularly various endoscopy types, computer technologies, various esophagoplasty types, methods of esophago-organ anastomosis formation, utilization of specialized suture and plastic materials, instrumental methods of placing anastomosis and tissue dissection, as well as modern progress in anesthesiology and reanimatology, unfortunately, failed to solve the problems encountered by outstanding surgeons in the last century $[1,2]$. This fact is confirmed by still high rate of postoperative complications and mortality (15\%).

The most severe complication that leads to the development of postoperative empyema and sepsis is failure of sutures especially of cervical anastomosis. It occurres in 9 $\%-17 \%$ of cases and leads to strictures of esophago-organ anastomosis in long-term postoperative period. Sometimes it requires repeated reconstructive surgery $[3,4]$. There is no tendency of decreasing of postoperative complications and mortality $[5,6]$.

Numerous studies, presented in modern scientific liter- ature, are devoted to various methods of preventing the leakage of hollow organs anastomoses, but unfortunately, the problem of anastomotic leakage is still urgent in surgery $[7,8,9]$.

\section{THE AIM}

The aim of the work is to improve the results of operative treatment of esophageal strictures by decreasing the rate of failure and stricture of cervical esophago-organ anastomoses.

\section{MATERIALS AND METHODS}

Biomedical Ethics Commission of Vinnytsya National Pirogov Memorial Medical University on observance of moral and legal rules in conducting medical research has established that clinical research were carried out in compliance with the main provisions of GCP (1996), Council of Europe Convention for Human Rights and Biomedicine (1997), World Medical Association Declaration of Helsinki on ethical principles for medical research involving human subjects (1964-2000) and Order of Ministry of Health of Ukraine № 281 of November 1, 2000. 
114 patients with esophageal strictures were studied between 2005 and 2019 that were treated at the Department of esophageal and gastro-intestinal diseases of state institution "V.T.Zaitsev Institute of General and Emergency Surgery of National Academy of Medical Sciences" (70 persons) and Thoracic Surgery Department of Vinnytsya Regional Pirogov Memorial Clinical Hospital (44 persons).

There were 45 patients with post-burn corrosive gullet strictures, 17 patients with postoperative corrosive strictures, 10 patients with peptic strictures secondary to reflux-esophagitis, 42 patients with esophageal cancer strictures. The patients were divided into two groups: the comparison group - 55 persons and the main group - 59 persons. Patients of comparison group underwent surgical treatment of esophageal strictures according to classic protocols and standards. In the main (experimental) group of patients we applied proposed diagnostic algorithm with prediction of complication risk and the designed method of esophago-organ anastomosis formation.

In the patients of main group logistic regression method was used to evaluate the role of certain factors in esophageal anastomotic failure after esophagoplasty according to unmatched case-control unbalanced design of the study. A total of 100 patients were studied, 52 of them had complications and 48 - without complications. The most significant predictors of postoperative complications were identified by modeling the risk of their development. By coefficient values, the risk of cervical esophago-organ anastomosis failure and associated complications was found to be increased in anemia, model coefficient $=2.0629, \mathrm{p}=0.0356$; with decrease albumin level - less than $25 \mathrm{~g} / \mathrm{l}$, model coefficient $=2.9323, \mathrm{p}=0.0117$; with diabetes mellitus, model coefficient $=3.1655, \mathrm{p}=0.0156$; total esophageal obstruction, model coefficient $=2.9962, \mathrm{p}=0.0104$. The application of the proposed treatment program reduces the risk of its failure, model coefficient $=-4.7125, \mathrm{p}=0.0657$ and application of the suggested instrumental method formation of esophago-organ cervical anastomosis in the neck significantly reduced the risk of its failure, model coefficient $=-6.4835, \mathrm{p}=0.0068$. When comparing informative value of full and reduced models, no significant differences were found, $(p=0.3534)$. Thus, the two models had similar prognostic value. As linear predictor consists of only six risk factors, the range of predicted risk of leakage development is wide - from $0 \%$ to $99.8 \%$.

According to the abovementioned estimates, the prognostic model is as follows:

$$
r=\{1+\exp (- \text { regpred })\}^{-1}
$$

where $r$ - prognostic risk of cervical esophago-organ anastomosis failure, exp - exponent, regpred - regression predictor variable,

regpred $=-\mathbf{6 . 1 2 2 4}+2.0629^{\star}$ anemia $+2.9323^{\star}$ hypoproteinemia $+3.1655^{\star}$ diabetes mellitus $+\mathbf{2 . 9 9 6 2}^{\star}$ total esophageal obstruction $-4.7125^{\star}$ application of the proposed treatment program $\mathbf{- 6 . 4 8 3 5 ^ { \star }}$ application of suggested method of anastomosis formation.

\section{RESULTS AND DISCUSSION}

After predicting the risk of complications of cervical anastomosis and if it exceeded $70 \%$, the patients were not operated on. They underwent intensive therapy in the intensive care unit to correct anemia, all kinds of metabolism, and dilatation of the stricture region by balloon dilation method or stenting with nitinol stents if possible. In the absence of conditions for balloon dilation and stenting gastrostomy by Witzel's method or Kader procedure were performed.

When prognostic risk of cervical esophago-organ anastomosis failure was $40-70 \%$, the patients underwent correction of concomitant pathology, anemia, protein and water-electrolyte metabolism in intensive care unit to be prepared for reconstructive surgery.

When anastomosis failure risk was less than $40 \%$, the patients underwent preoperative preparation in the surgical department followed by reconstructive surgery.

The suggested instrumental method of formation of esophago-organ anastomosis was applied in 7 patients (useful model patent of Ukraine № 132523 of 25.02.2019). According to this method, during esophageal reconstructive procedure for strictures or esophageal cancer after esophageal extirpation and formation of the transplant and its placement on the neck area (through the posterior mediastinum in plastics with gastric tube or retrosternal plastics of the esophagus with the colon), the removable head of the circular stapler is fixed in the remnant of the esophagus and purse-string-type closure is performed. For anastomosis creation, the circular stapler $\mathrm{CH} 29$ is inserted through the proximal portion of the transplant in the neck region, and end-to-side mechanical anastomosis is formed (Fig. 1).

After mechanical suturing, circular stapler is opened and extracted from the corresponding organ lumens. Then, gastric tube No 18 is inserted through the created mechanical anastomosis. Mechanical suture line is reinforced by quilted sutures, beginning and ending on the transplant at a distance of $1 \mathrm{~cm}$ from the line of instrumental anastomosis. First, all sutures are placed, and then they are tied in turn, thus placing the esophageal stump in the graft (Figure 2, Figure 3). After formation of anastomosis, the excessive part of the transplant (gastric tube or colon) is cut off with a linear stapler.

The results of operative treatment in patients with esophageal strictures showed the development of early postoperative complications in 59 individuals (51.75\%). In the postoperative period six patients died: four - in the comparison group and two - in the main group. In the main group, where treatment program with predicting the risk of complications of cervical esophago-organ anastomosis and suggested instrumental method of its formation were used, the patients demonstrated steady improvement of postoperative general clinical and laboratory indices. Failure of cervical esophago-organ anastomosis and esophageal strictures occurred in 7 patients $(11.86 \%)$ of main group and 20 patients (36.36\%) of the comparison group $(p<0.05)$. In our study there were no cases of cervical anastomosis failure using the proposed method of its 


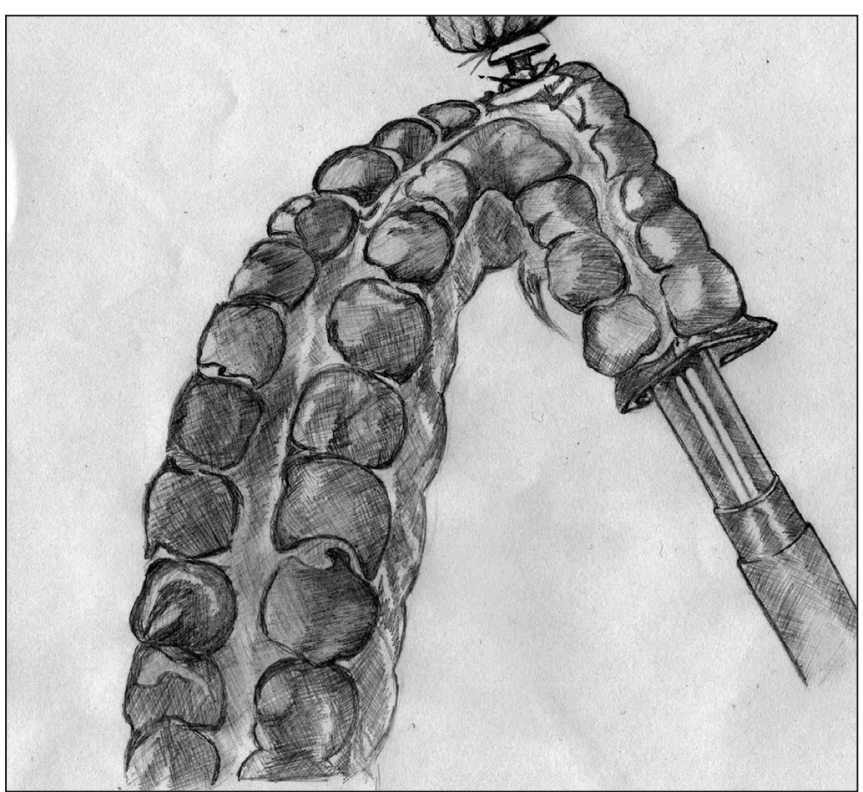

Fig. 1. Formation of mechanical end-to-side anastomosis

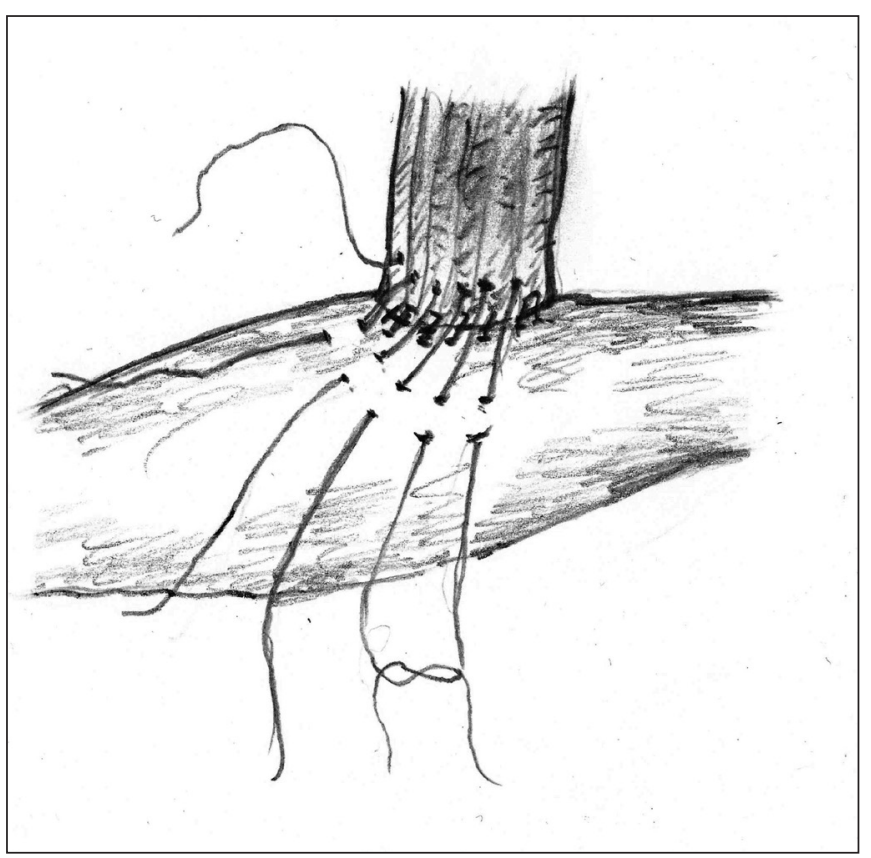

Fig. 2. Reinforcement of mechanical suture line with quilted sutures

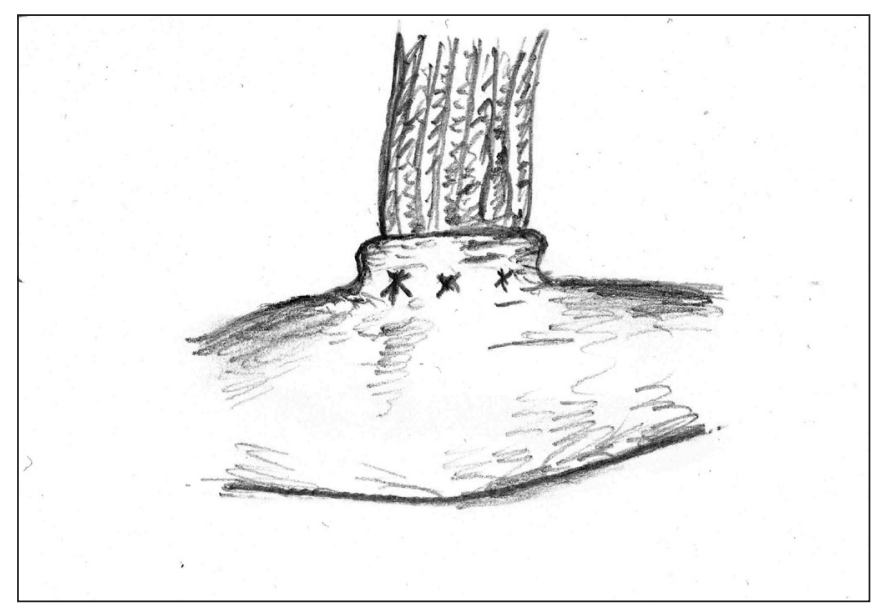

Fig. 3. Invagination of esophageal stump in the transplant formation. So the proposed method of formation of mechanical esophago-organ anastomosis reduces the number of complications of cervical anastomosis as compared to traditional method $[10,11]$.

\section{CONCLUSIONS}

Application of method predicting the risk of complications of cervical anastomosis, treatment program and instrumental method of formation of esophago-organ anastomosis resulted in reduced incidence of failure and strictures of esophago-organ anastomosis; decreased time of hospitalization - from $28.2 \pm 1.1$ to $21.5 \pm 0.5$ bed-days ( $\mathrm{p}<0.001$ ), postoperative period - from $20.5 \pm 1.1$ to $16.1 \pm$ 0.7 bed-days ( $\mathrm{p}<0.01$ ); decreased postoperative mortality - from $7.27 \%$ to $3.39 \%$.

\section{REFERENCES}

1. Thomas N. With minimally invasive esophagectomy, thoracic surgeons must avoid falling into the same trap again! Semin Thorac Cardiovasc Surg. 2015; 27: 216-217.

2. Mariette C., Meunier B., Pezet D. Hybrid minimally invasive versus open oesophagectomy for patients with oesophageal cancer: a multicenter, open-label, randomized phase III controlled trial, the MIRO trial. J Clin Oncol. 2015; 33 .

3. Korst R.J., Port J.L., Lee P.C. et al. Intrathoracic manifestations of cervical anastomotic leaks after transthoracic esophagectomy for carcinoma. Ann Thorac Surg. 2005; 80: 1185-1190.

4. van Heijl M., van Wijngaarden A.K., Lagarde S.M. et al. Intrathoracic manifestations of cervical anastomotic leaks after transhiatal and transthoracic oesophagectomy. Br J Surg. 2010; 97: 726-731.

5. Finks J.F., Osborne N.H., Birkmeyer J.D. Trends in hospital volume and operative mortality for high-risk surgery. N Engl J Med. 2011; 364: 2128-2137.

6. Talsma A.K., Lingsma H.F., Steyerberg E.W. et al. The 30-day versus in-hospital and 90-day mortality after esophagectomy as indicators for quality of care. Ann Surg. 2014; 260: 267-273.

7. Markar S.R., Arya S., Karthikesalingam A. et al. Technical factors that affect anastomotic integrity following esophagectomy: systematic review and meta-analysis. Ann Surg Oncol. 2013; 20: 4274-4281.

8. Irino T., Tsai J.A., Ericson J. et al. Thoracoscopic side-to-side esophagogastrostomy by use of linear stapler - a simplified technique facilitating a minimally invasive Ivor-Lewis operation. Langenbecks Arch Surg. 2016; 401: 315-322.

9. Shaprynskyi V.O., Shaprinskiy Y.V., Karyi Y.V., et al. Operative treatment of corrosive esophageal strictures. Wiadomości Lekarskie. 2018; 71:323 -325 .

10. Low D.E., Alderson D., Cecconello I. et al. International consensus on standardization of data collection for complications associated with esophagectomy: esophagectomy complications consensus group (ECCG). Ann Surg. 2015; 262: 286-294.

11. Straatman J., van der Wielen N., Cuesta M.A. et al. Minimally invasive versus open esophagectomy resection. Three-year follow-up of the previously reported randomized controlled trial: the TIME trial. Ann Surg. 2017; 266(2): 232-236.

The article is a part of complex scientific research work at Surgery Department of National Pirogov Memorial Medi- 
cal University, Vinnytsia, «Development and improvement of advanced technologies in surgical treatment and prevention of postoperative complications in patients with diseases of abdominal and chest cavities», state registration number $0113 U 007692$.

\section{ORCID and contributionship:}

Volodymyr O. Shaprynskyi: 0000-0002-3890-6217 A,B

Yevhen V. Shaprynskyi: 0000-0002-4949-3163 ${ }^{B, C, D}$

Mustafa Bassam Hussein: 0000-0003-1166-1798 ${ }^{B, C, F}$

Oleg O. Vorovskyi: 0000-0002-8933-3965 E,F

Yaroslav V. Karyi: 0000-0003-1578-9019 D,E,F

Liudmyla A. Shaprynska: 0000-0001-8185-6887 B,F

Serhii P. Dmytryshyn: 0000-0002-3537-7364 ${ }^{B, F}$

\section{Conflict of interest:}

The Authors declare no conflict of interest.

\section{CORRESPONDING AUTHOR}

Yevhen V. Shaprynskyi

National Pirogov Memorial Medical University

56 Pirogov st., 21018 Vinnytsia, Ukraine

tel: +380632861199

e-mail: evgensh20078@gmail.com

Received: 11.09 .2019

Accepted:08.06.2020

A - Work concept and design, B - Data collection and analysis, C - Responsibility for statistical analysis,

$\mathbf{D}$-Writing the article, $\mathbf{E}$-Critical review, $\mathbf{F}$ - Final approval of the article 